\title{
Clinical profile and outcomes of COVID-19 patients with acute kidney injury: a tertiary centre experience from South India
}

\author{
Chaganti Sindhu ${ }^{1} \cdot$ Pallavi Prasad $^{1,2} \mathbb{D} \cdot$ Ramprasad Elumalai $^{1} \cdot$ Jayakumar Matcha $^{1}$
}

Received: 24 June 2021 / Accepted: 10 August 2021 / Published online: 16 August 2021

(c) Japanese Society of Nephrology 2021

\begin{abstract}
Aim The rates of development of acute kidney injury (AKI) in COVID-19 have been variably reported from across the world. Prevalence and outcomes of AKI in hospitalised COVID-19 patients in India has not been studied well.

Methods This was a retrospective observational study amongst adult hospitalised COVID-19 patients admitted at a tertiary care centre between May 1 and October 31,2020. We estimated the prevalence of AKI and outcomes including mortality and acute kidney disease (AKD) at the time of discharge. Regression analysis was done to study the factors associated with mortality and AKD.

Results Out of 2650 hospitalised patients with COVID-19, 190 (7.2\%) patients developed AKI. Mean age of patients with AKI was 62.6 years, $81.6 \%$ were male. Comorbidities included diabetes mellitus in $72.1 \%$, hypertension in $66.8 \%$, heart disease in $30 \%$ and chronic kidney disease (CKD) in 22.6\%. Most patients had stage 1 AKI (71.1\%). Overall mortality in patients with AKI was $22.1 \%, 75 \%$ in those requiring dialysis and $74.5 \%$ in those requiring ICU. Amongst survivors without pre-existing CKD, $40.9 \%$ patients had acute kidney disease at the time of discharge. Higher age, stage 3 AKI and need for mechanical ventilation were associated with higher mortality. On multivariable regression, factors associated with AKD at discharge included pre-existing heart disease and severe albuminuria during hospitalisation.

Conclusion In our study population, we found a low prevalence of AKI. Mortality was high in AKI patients requiring ICU care and dialysis. Amongst survivors, a significant percentage had AKD at the time of discharge.
\end{abstract}

Keywords AKI $\cdot$ CKD $\cdot$ COVID-19 $\cdot$ Kidney $\cdot$ Mortality

\section{Introduction}

The SARS-CoV-2 (severe acute respiratory syndrome coronavirus 2), notorious to cause respiratory failure, not only affects the respiratory system but has myriad other manifestations in various body systems. It is now known to cause haematological, gastrointestinal, renal, dermatologic, neurologic, and psychiatric complications, making it a multisystem disease [1]. Amongst renal manifestations, acute kidney injury (AKI) is a well-established complication of COVID-19 infection. There are various pathophysiological mechanisms by which AKI develops in COVID-19.

Pallavi Prasad

pallaviprasad1986@gmail.com

1 Department of Nephrology, Sri Ramachandra Institute of Higher Education and Research, Chennai, India

2 37\&38, Sri Lakshmi Nagar, 10th Cross Street, Valasarvakkam, Chennai 600087, India
Although acute tubular injury is the most common cause of AKI in COVID-19, other mechanisms described include direct viral invasion, rhabdomyolysis, thrombotic microangiopathy, interstitial nephritis, oxalate nephropathy and glomerulopathies including collapsing glomerulopathy and crescentic glomerulonephritis [2].

The prevalence of AKI in patients with COVID-19 has been variably reported between 0.5 and $75 \%$ from various countries and centres [3]. AKI has also been seen to be an independent factor associated with mortality in patients with COVID-19 [1].

India now has one of the highest number of reported cases of COVID-19, second only to the United States of America [4]. Despite this, data from India regarding prevalence and outcomes of AKI in COVID-19 are sparse [5-8]. We aimed to study the prevalence of AKI in hospitalised patients with COVID-19 and their outcomes at a tertiary care centre in India. 


\section{Methods}

\section{Study design}

This was a retrospective observational study done in a tertiary care health centre in India. Data were obtained using the electronic health record system. The study was approved by the Institutional Ethics Committee before the commencement of the study. Informed consent was not obtained at individual level, given the retrospective nature of the analysis of electronic medical record.

\section{Study population}

All adult patients with positive results by polymerase chain reaction (PCR) testing of a nasopharyngeal sample for SARS-CoV-2 who were hospitalised from May 1, 2020 to Oct 31, 2020 were screened for renal function abnormalities in the form of increased serum creatinine (Scr), electrolyte abnormalities and urinary abnormalities. Patients testing positive for COVID-19 with age $<18$ years were excluded from the study. For calculation of prevalence of AKI, we used this study population and excluded patients with stage 5 CKD (chronic kidney disease) on dialysis. Patients fulfilling AKI KDIGO criteria amongst this population were included for mortality and outcome analysis.

\section{Outcomes}

The primary outcome was in-hospital mortality in patients with AKI. Secondary outcomes were recovery from AKI and acute kidney disease at the time of discharge.

\section{Definitions and measurements}

AKI was defined according to KDIGO (Kidney Disease: Improving Global Outcomes) criteria as follows: stage 1, as an increase in Scr level by $0.3 \mathrm{mg} / \mathrm{dL}$ within $48 \mathrm{~h}$ or $1.5-1.9$ times increase in Scr level from baseline within 7 days; stage 2, as 2-2.9 times increase in Scr level within 7 days; and stage 3, as 3 or more times increase in Scr level within 7 days or initiation of dialysis [9]. Urine output documentation in electronic health record was unreliable. Hence, urine output criteria was not used to define AKI. Patients were stratified according to the most severe AKI stage attained during their hospital stay. Comorbidities including diabetes mellitus, hypertension and CKD were defined as per history documentation by the admitting physician. For patients without prior history of CKD, estimated baseline creatinine was calculated using the Modification of Diet in Renal Disease (MDRD) study equation assuming that baseline eGFR is
$75 \mathrm{~mL} / \mathrm{min}$ per $1.73 \mathrm{~m}^{2}$ [9]. In patients without prior history of CKD, recovery of kidney function at discharge was defined as recovered if serum creatinine was within limits of estimated baseline creatinine and acute kidney disease (AKD) if discharge creatinine was above estimated baseline creatinine.

Proteinuria was defined as $1+$ or more on dipstick urine analysis. Severe albuminuria was defined as patients having $3+$ or $4+$ albuminuria on dipstick. Hematuria was defined as $>5 \mathrm{RBC} / \mathrm{hpf}$ on routine urine analysis. Urinary tract infection (UTI) was defined by presence of positive urine culture along with signs and symptoms consistent with cystitis/pyelonephritis.

Severity of COVID was defined as mild for patients without evidence of breathlessness or hypoxia (normal saturation with $\mathrm{SpO}_{2}>94 \%$ on room air). Moderate COVID was defined for patients with dyspnoea and/or hypoxia with $\mathrm{SpO}_{2}$ between 90 and $94 \%$ on room air or respiratory rate $(R R) \geq 24 / \mathrm{min}$. Severe COVID was defined for patients with clinical signs of pneumonia plus one of the following: RR $>30$ breaths/min, severe respiratory distress, $\mathrm{SpO}_{2}<90 \%$ on room air [10].

\section{Statistical analysis}

Descriptive statistics included mean for continuous measures with normal distribution, median and interquartile range (IQR) for continuous measures with skewed distribution and proportions for categorical measures. We compared patient characteristics between AKI patients who survived versus those who died using Chi-square test or Fishers exact tests for categorical variables and Wilcoxon-Mann-Whitney $U$ test for continuous variables.

To evaluate risk factors for mortality amongst patients with AKI and to evaluate predictors of renal recovery at discharge, we used univariable and multivariable regressions.

For survival analysis, we generated Kaplan-Meier survival curves for patients with AKI stages 1-3 using in-hospital mortality as the outcome and used Log rank test to compare the curves. Survivors were censored at the time of discharge.

All statistical tests were 2-sided, and $p<0.05$ was considered statistically significant. SPSS version 23 was used for statistical analysis.

\section{Results}

A total of 2657 adult patients who tested positive for COVID-19 were admitted between May 1, 2020 and October 31, 2020. After applying relevant exclusion criteria, 2650 patients were selected for calculating prevalence of 
Fig. 1 Consort diagram showing patient selection from study population

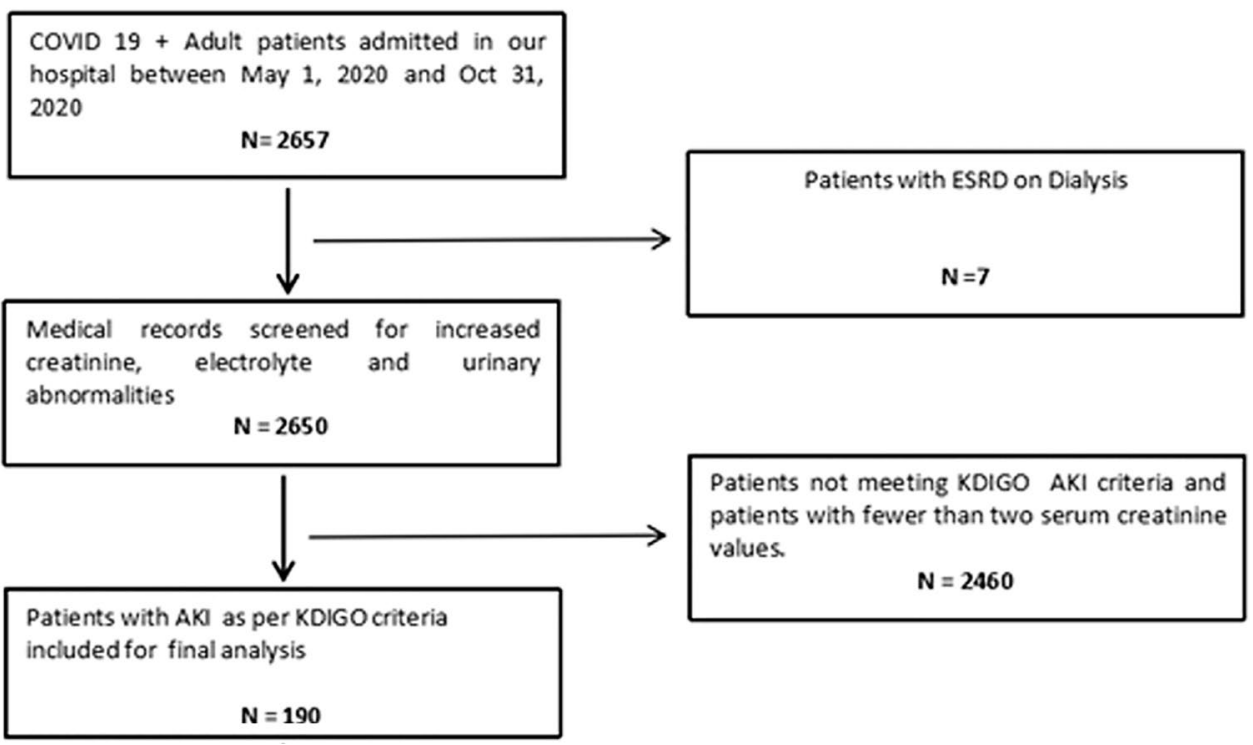

AKI (Fig. 1). Amongst these 2650 patients, 4.4\% $(n=117)$ required ICU admission.

The prevalence of AKI amongst hospitalised adult patients with COVID-19 was $7.2 \%(n=190)$. Demographic and clinical characteristics of patients who developed AKI is presented in Table 1. Mean age was 62.6 years, $81.6 \%$ were male. Comorbidities included diabetes mellitus in $72.1 \%$, hypertension in $66.8 \%$, heart disease (including CAD, valvular heart disease, heart failure) in $30 \%$ and CKD in $22.6 \%$. Severity of COVID-19 included mild disease in $36.8 \%$, moderate in $33.1 \%$ and severe in $30 \%$.

The prevalence of urinary abnormalities in the patient population $(n=2650)$ included proteinuria in $36.7 \%$, microscopic hematuria $1.8 \%$, urinary tract infection in $2 \%$. Hyponatremia was present in $19 \%$ and hypokalemia in $4.4 \%$.

\section{AKI timing and severity}

Out of the 190 patients with AKI, 72.6\% (N=138) patients had AKI at the time of presentation to the hospital. The mean time of admission to AKI (in days) was $0.58 \pm 1.33$ (range was 0-12 days). Patients were classified as per highest stage of AKI during hospital stay. 135 (71.1\%) participants had AKI Stage 1, 29 (15.3\%) had AKI Stage 2 and 26 (13.7\%) had AKI Stage 3.

Amongst those with AKI, 28.9\% $(n=55)$ required ICU care and $4.2 \%(n=8)$ of the participants needed renal replacement therapy. Mode of renal replacement therapy was sustained low-efficiency dialysis (SLED) in $n=7$ and intermittent hemodialysis in $\mathrm{n}=1$.

\section{Mortality in patients with AKI}

Out of the 190 patients with AKI, 148 (77.9\%) were discharged and $42(22.1 \%)$ patients expired. Amongst 55 (28.9\%) patients in ICU with AKI, mortality was seen in $41(74.5 \%)$ patients, which accounted for $97.6 \%$ of mortality in patients with AKI. Amongst those requiring renal replacement therapy, 75\% ( $n=6)$ suffered mortality. Figure 2 demonstrates the Kaplan-Meier survival curves for patients with AKI stages 1, 2 and 3. The clinical characteristics of those who expired versus those who were discharged were compared (Table 1) and logistic regression was used for assessing risk factors for death in those with AKI (Table 2).

On logistic regression (univariable), factors associated with mortality included: higher age (70 years vs 60.6 years), dyspnoea at presentation, pre-existing cardiovascular diseases, hypoxemia at presentation, stage 3 AKI, D-dimer $>0.5 \mu \mathrm{g} / \mathrm{L}$, presence of secondary bacterial/fungal infection, need for inotropes, need for mechanical ventilation and need for renal replacement therapy (RRT). AKI at presentation had a lower odds ratio $(\mathrm{OR}=0.26 . p<0.001)$ for developing mortality than AKI developing in-hospital. On multivariable logistic regression (using demographics, comorbidities and severity of illness markers), factors associated with mortality in patients with AKI included higher age (60.6 years versus 70 years, $\mathrm{OR}=1.07, p=0.015$ ), development of stage 3 AKI (OR $=13.82, p=0.012)$ and need for mechanical ventilation (odds ratio $52.06, p<0.001$ ).

\section{Outcome of AKI in survivors}

Amongst the 190 patients who developed AKI, 148 $(77.8 \%)$ were discharged. Of these, 33 had pre-existing 
Table 1 Demographic and clinical characteristics of patients who developed AKI

\begin{tabular}{|c|c|c|c|c|}
\hline \multirow[t]{2}{*}{ Parameters } & \multirow[t]{2}{*}{ All AKI } & \multicolumn{2}{|l|}{ Mortality } & \multirow[t]{2}{*}{$p$ value } \\
\hline & & Present $(n=42)$ & Absent $(n=148)$ & \\
\hline Age in years (mean) & $62.63 \pm 13.83$ & $70.05 \pm 13.13$ & $60.53 \pm 13.33$ & $<0.001^{\dagger}$ \\
\hline \multicolumn{5}{|l|}{ Gender } \\
\hline Male & $155(81.6 \%)$ & $35(83.3 \%)$ & $120(81.1 \%)$ & $0.740^{\ddagger}$ \\
\hline \multicolumn{5}{|l|}{ Clinical features at presentation } \\
\hline Fever & $161(84.7 \%)$ & $33(78.6 \%)$ & $128(86.5 \%)$ & $0.208^{\ddagger}$ \\
\hline Cough & $103(54.2 \%)$ & $23(54.8 \%)$ & $80(54.1 \%)$ & $0.935^{\ddagger}$ \\
\hline Dyspnoea & $100(52.6 \%)$ & $31(73.8 \%)$ & $69(46.6 \%)$ & $0.002^{\ddagger}$ \\
\hline Sore throat & $40(21.1 \%)$ & $3(7.1 \%)$ & $37(25.0 \%)$ & $0.012^{\ddagger}$ \\
\hline GI symptoms & $28(14.7 \%)$ & $6(14.3 \%)$ & $22(14.9 \%)$ & $0.926^{\ddagger}$ \\
\hline Headache & $4(2.1 \%)$ & $0(0.0 \%)$ & $4(2.7 \%)$ & $0.577^{\S}$ \\
\hline Myalgia & $31(16.3 \%)$ & $7(16.7 \%)$ & $24(16.2 \%)$ & $0.944^{\ddagger}$ \\
\hline Loss of taste/smell & $13(6.8 \%)$ & $4(9.5 \%)$ & $9(6.1 \%)$ & $0.489^{3}$ \\
\hline Oliguria & $6(3.2 \%)$ & $6(14.3 \%)$ & $0(0.0 \%)$ & $<0.001^{\S}$ \\
\hline Hypotension & $18(9.5 \%)$ & $14(33.3 \%)$ & $4(2.7 \%)$ & $<0.001^{\S}$ \\
\hline Hypoxemia & $116(61.1 \%)$ & $41(97.6 \%)$ & $75(50.7 \%)$ & $<0.001^{\ddagger}$ \\
\hline \multicolumn{5}{|l|}{ Comorbidities } \\
\hline $\mathrm{DM}$ & $137(72.1 \%)$ & $35(83.3 \%)$ & $102(68.9 \%)$ & $0.066^{\ddagger}$ \\
\hline HTN & $127(66.8 \%)$ & $31(73.8 \%)$ & $96(64.9 \%)$ & $0.277^{\ddagger}$ \\
\hline Heart disease & $57(30.0 \%)$ & $19(45.2 \%)$ & $38(25.7 \%)$ & $0.015^{\ddagger}$ \\
\hline Prior CVA & $10(5.3 \%)$ & $3(7.1 \%)$ & $7(4.7 \%)$ & $0.463^{\S}$ \\
\hline CKD & $43(22.6 \%)$ & $10(23.8 \%)$ & $33(22.3 \%)$ & $0.875^{\ddagger}$ \\
\hline Haemoglobin (g/dL) & $12.00(10.62-13.20)$ & $11.1(8.77-12.95)$ & $12(11-13.3)$ & $0.005^{\dagger}$ \\
\hline TLC (/cu.mm) & $6950.00(4700.00-10,675.00)$ & $10,550(6525-19,650)$ & $6400(4600-9625)$ & $<0.001 \dagger$ \\
\hline $\operatorname{ESR}(\mathrm{mm} / \mathrm{h})$ & $34.50(21.00-63.25)$ & $80(56-90)$ & $30(20-50)$ & $<0.001^{\dagger}$ \\
\hline Total bilirubin (mg/dL) & $0.60(0.40-0.80)$ & $0.75(0.5-1.1)$ & $0.53(0.4-0.8)$ & $0.001^{\dagger}$ \\
\hline SGOT (U/L) & $34.50(25.25-52.00)$ & $50.5(31-119)$ & $33(24-44.25)$ & $<0.001^{\dagger}$ \\
\hline SGPT (U/L) & $24.50(17.00-44.00)$ & $40.5(20-84.25)$ & $23(16-37.75)$ & $<0.001^{\dagger}$ \\
\hline S. albumin (g/dL) & $3.50(3.10-3.80)$ & $3.15(2.6-3.48)$ & $3.6(3.3-3.9)$ & $<0.001^{\dagger}$ \\
\hline PT & $12.20(11.72-13.28)$ & $13.3(12.1-14.5)$ & $12.2(11.7-12.5)$ & $<0.001^{\dagger}$ \\
\hline S. uric acid (mg/dL) & $5.00(4.40-7.30)$ & $7.65(4.5-9.38)$ & $4.7(4.3-6.6)$ & $<0.001^{\dagger}$ \\
\hline S. sodium (mEq/L) & $133.00(130.00-136.00)$ & $132.5(129.25-138.25)$ & $133(130-136)$ & $0.715^{\dagger}$ \\
\hline S. potassium $(\mathrm{mEq} / \mathrm{L})$ & $4.40(3.90-5.10)$ & $5.1(4-5.4)$ & $4.40(3.88-4.9)$ & $0.006^{\dagger}$ \\
\hline S. $\mathrm{HCO}_{3}(\mathrm{mEq} / \mathrm{L})$ & $20.00(17.00-23.00)$ & $16(12-19)$ & $21(18-24)$ & $<0.001^{\dagger}$ \\
\hline S. calcium (mg/dL) & $8.70(8.40-8.80)$ & $8.5(8.2-8.8)$ & $8.7(8.4-8.8)$ & $0.132^{\dagger}$ \\
\hline S. phosphate (mg/dL) & $3.30(2.40-3.80)$ & $3.4(3.12-4.5)$ & $3.2(2.3-2.6)$ & $0.012^{\dagger}$ \\
\hline $\mathrm{CRP}(\mathrm{mg} / \mathrm{L})$ & $8.00(3.00-14.00)$ & $17(11-30)$ & $5(2.3-11.83)$ & $<0.001^{\dagger}$ \\
\hline Ferritin $(\mathrm{ng} / \mathrm{mL})$ & $302.50(167.50-564.50)$ & $466(315.75-872.75)$ & $265(145-519.75)$ & $<0.001^{\dagger}$ \\
\hline $\mathrm{LDH}(\mathrm{U} / \mathrm{L})$ & $325.00(236.25-462.75)$ & $482.5(387-714.25)$ & $296.5(233-429.5)$ & $<0.001^{\dagger}$ \\
\hline D-Dimer $(\mu \mathrm{g} / \mathrm{mL})$ & $0.92(0.54-2.30)$ & $2.4(1.33-6.3)$ & $0.8(0.5-1.85)$ & $<0.001^{\dagger}$ \\
\hline S. creatinine $(\mathrm{mg} / \mathrm{dL})$ at admission & $1.50(1.10-1.87)$ & $1.3(0.9-1.78)$ & $1.5(1.2-1.9)$ & $0.079^{\dagger}$ \\
\hline S. creatinine $(\mathrm{mg} / \mathrm{dL})$ peak value & $1.60(1.20-2.10)$ & $1.55(1.2-3.5)$ & $1.6(1.2-1.92)$ & $0.171^{\dagger}$ \\
\hline S. creatinine $(\mathrm{mg} / \mathrm{dL})$ at discharge/death & $1.20(0.80-1.50)$ & $1.4(1.02-2.6)$ & $1.1(0.8-1.4)$ & $0.001^{\dagger}$ \\
\hline Severe albuminuria & $53(38.7 \%)$ & $9(22.5 \%)$ & $46(30.6 \%)$ & 0.392 \\
\hline Microscopic hematuria & $16(8.4 \%)$ & $9(21.4 \%)$ & $7(4.7 \%)$ & $0.002^{\S}$ \\
\hline Pyuria & $98(51.6 \%)$ & $24(57.1 \%)$ & $74(50.0 \%)$ & $0.414^{\ddagger}$ \\
\hline Urine culture positive/UTI & $44(23.2 \%)$ & $14(33.3 \%)$ & $30(20.3 \%)$ & $0.077^{\ddagger}$ \\
\hline AKI stage & & & & $<0.001$ \\
\hline Stage 1 & $135(71.1 \%)$ & $20(47.6 \%)$ & $115(77.7 \%)$ & \\
\hline
\end{tabular}


Table 1 (continued)

\begin{tabular}{|c|c|c|c|c|}
\hline \multirow[t]{2}{*}{ Parameters } & \multirow[t]{2}{*}{ All AKI } & \multicolumn{2}{|l|}{ Mortality } & \multirow[t]{2}{*}{$p$ value } \\
\hline & & Present $(n=42)$ & Absent $(n=148)$ & \\
\hline Stage 2 & $29(15.3 \%)$ & $5(11.9 \%)$ & $24(16.2 \%)$ & \\
\hline Stage 3 & $26(13.7 \%)$ & $17(40.5 \%)$ & $9(6.1 \%)$ & \\
\hline AKI at presentation & $138(72.6 \%)$ & $22(52.4 \%)$ & $116(78.4 \%)$ & \\
\hline Time of admission to AKI (days) & $0.00(0.00-1.00)$ & $0(0-2)$ & $0(0-0)$ & $<0.001$ \\
\hline Sepsis/secondary bacterial or fungal infection & $37(19.5 \%)$ & $26(61.9 \%)$ & $11(7.4 \%)$ & $<0.001^{\ddagger}$ \\
\hline Severity of COVID & & & & $<0.001^{\ddagger}$ \\
\hline Mild & $70(36.8 \%)$ & $0(0.0 \%)$ & $70(47.3 \%)$ & \\
\hline Moderate & $63(33.1 \%)$ & $1(2.4 \%)$ & $62(39.9 \%)$ & \\
\hline Severe & $57(30 \%)$ & $41(97.6 \%)$ & $16(12.8 \%)$ & \\
\hline \multicolumn{5}{|l|}{ Medications received in hospital } \\
\hline Glucocorticoids & $157(82.6 \%)$ & $41(97.6 \%)$ & $116(78.4 \%)$ & 0.004 \\
\hline Remdesivir & $38(20.0 \%)$ & $9(21.4 \%)$ & $29(19.6 \%)$ & $0.793^{\ddagger}$ \\
\hline Antibiotics & $68(35.8 \%)$ & $30(71.4 \%)$ & $38(25.7 \%)$ & $<0.001^{\ddagger}$ \\
\hline Antifungal & $12(6.3 \%)$ & $7(16.7 \%)$ & $5(3.4 \%)$ & $0.005^{\S}$ \\
\hline Anticoagulants & $163(85.8 \%)$ & $42(100.0 \%)$ & $121(81.8 \%)$ & $0.003^{\ddagger}$ \\
\hline Supportive therapy: inotropes & $33(17.4 \%)$ & $29(69.0 \%)$ & $4(2.7 \%)$ & $<0.001^{\ddagger}$ \\
\hline Supportive therapy: mechanical ventilation & $43(22.6 \%)$ & $36(85.7 \%)$ & $7(4.7 \%)$ & $<0.001^{\ddagger}$ \\
\hline Supportive therapy: RRT & $8(4.2 \%)$ & $6(9.5 \%)$ & $2(1.3 \%)$ & $<0.001^{\S}$ \\
\hline Duration of hospital stay (days) & $9.00(6.00-14.00)$ & $12(7-17.75)$ & $9(5-12)$ & $0.013^{\dagger}$ \\
\hline
\end{tabular}

Values mentioned are in percentages or median (with interquartile range) unless specified otherwise. Tests used: ${ }^{\dagger}$ Wilcoxon-Mann-Whitney $U$ test, ${ }^{\ddagger}$ Chi-squared test, ${ }^{\S}$ Fisher’s exact test

$A K I$ acute kidney injury; DM diabetes mellitus; $H T N$ : hypertension; $C K D$ : chronic kidney disease; $C V A$ cerebrovascular accident; $R R T$ renal replacement therapy; TLC total leucocyte count; $E S R$ erythrocyte sediment rate; $S G O T$ serum glutamic-oxaloacetic transaminase; $S G P T$ serum glutamic-pyruvic transaminase; $P T$ prothrombin time; $\mathrm{HCO}_{3}$ bicarbonate; $\mathrm{CRP}$ C-reactive protein; $L D H$ lactate dehydrogenase

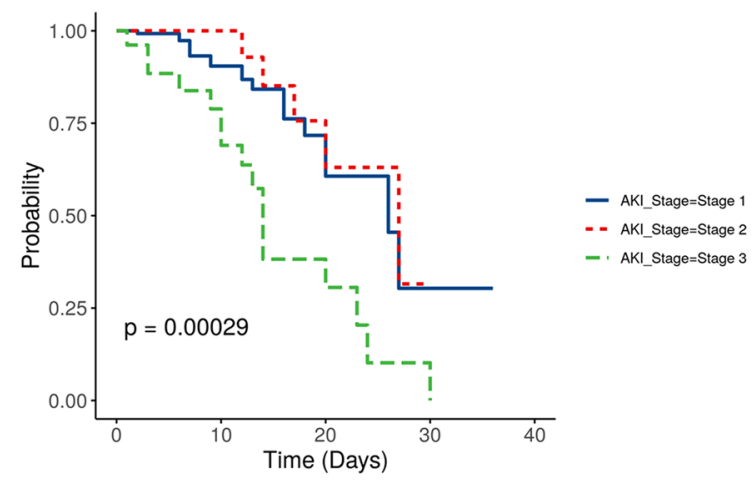

\begin{tabular}{ccccccccc}
\hline AKI Stage & Total N & Events & Censored & $\begin{array}{c}\text { Mean } \\
\text { Survival }\end{array}$ & $\begin{array}{c}95 \% \text { Cl for } \\
\text { Mean }\end{array}$ & $\begin{array}{c}\text { Median } \\
\text { Survival }\end{array}$ & $\begin{array}{c}95 \% \text { Cl For } \\
\text { Median }\end{array}$ & $\begin{array}{c}\text { P Value } \\
20-\text { NA }\end{array}$ \\
Stage 1 & 135.0 & 19.0 & 116.0 & 24.7 & $20.64-28.76$ & 26.0 & $\begin{array}{c}\text { Log Rank } \\
\text { Test: } p= \\
<0.001\end{array}$ \\
Stage 2 & 29.0 & 5.0 & 24.0 & 24.0 & $20.14-27.94$ & 27.0 & $20-$ NA \\
Stage 3 & 26.0 & 16.0 & 10.0 & 15.5 & $11.76-19.24$ & 14.0 & $12-$ NA \\
\hline
\end{tabular}

Fig. 2 Kaplan-Meier survival curves for patients with AKI stage 1, 2 and 3 
Table 2 Factors associated with mortality in patients with AKI (univariable and multivariable regressions)

\begin{tabular}{lcl}
\hline Clinical characteristic & OR (univariable) & OR (multivariable) \\
\hline Age (years) & $1.06(1.03-1.09, p<0.001)$ & $1.07(1.02-1.14, p=0.015)$ \\
Dyspnoea at presentation & $2.83(1.35-6.33, p=0.008)$ & $1.36(0.26-7.98, p=0.716)$ \\
Diabetes mellitus & $2.51(1.05-7.01, p=0.054)$ & $2.76(0.53-15.96, p=0.235)$ \\
Heart disease & $2.13(1.02-4.40, p=0.043)$ & $0.87(0.17-4.16, p=0.860)$ \\
Hypoxemia at presentation & $36.03(7.50-647.65, p<0.001)$ & $17.05(0.85-1044, p=0.118)$ \\
Stage 3 AKI & $9.74(4.01-24.84, p<0.001)$ & $13.82(2.07-133, p=0.012)$ \\
AKI at presentation & $0.26(0.12-0.54, p<0.001)$ & $1.28(0.31-5.89, p=0.739)$ \\
D-Dimer $>0.5 \mu \mathrm{g} / \mathrm{mL}$ & $7.93(2.29-50.06, p=0.006)$ & $1.45(0.13-26.09, p=0.778)$ \\
Absence of secondary infection & $0.07(0.03-0.15, p<0.001)$ & $0.86(0.15-5.70, p=0.870)$ \\
Need for inotropes & $48.00(17.79-149.73, p<0.001)$ & $2.54(0.36-15.60, p=0.318)$ \\
Mechanical ventilation & $86.17(30.77-283.50, p<0.001)$ & $52.06(7.79-554, p<0.001)$ \\
Need for renal replacement therapy & $13.45(2.95-94.68, p=0.002)$ & $0.11(0.00-3.65, p=0.179)$ \\
\hline
\end{tabular}

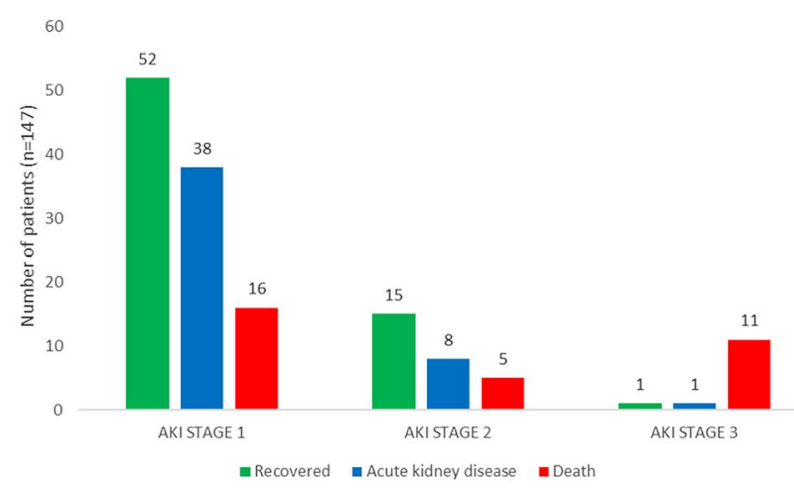

Fig. 3 Outcomes of different stages of AKI (excluding CKD)

CKD, 2 of whom were discharged on dialysis. Baseline creatinine was not available for all CKD patients; hence, they were excluded from analysis of recovery of kidney function.

The remaining 115 patients were classified on the basis of outcome of AKI at the time of discharge from hospitalrecovered or acute kidney disease. Baseline creatinine was assigned by imputation on basis of eGFR $75 \mathrm{~mL} /$ $\mathrm{min} / 1.73 \mathrm{~m}^{2}$ as per KDIGO AKI guidelines 2012. We found that $68(59.1 \%)$ patients recovered completely from AKI and 47 (40.9\%) had AKD at the time of discharge. Figure 3 illustrates the outcomes of patients in various AKI stages (excluding patients with CKD).
Logistic regression identified the following as predictive factors for AKD at the time of discharge (Table 3): older age (63.4 versus 56.7 years), pre-existing hypertension, pre-existing heart disease, severe albuminuria during hospitalisation (defined as urine dipstick proteinuria $>3+$ ). On multivariable regression (using demographics, comorbidities and severity of illness markers), only pre-existing hypertension and severe albuminuria during hospitalisation were associated with AKD at the time of discharge. $\mathrm{AKI}$ at presentation was associated with a lower odds ratio $(\mathrm{OR}=0.25, p=0.023)$ for AKD at discharge, implying that in-hospital AKI was associated with higher chances of AKD at discharge.

\section{Discussion}

The prevalence of AKI in COVID-19 has been variably reported from centres across the world. Early studies from China estimated the prevalence of AKI to be between 0.5 and 7\% [11-15]. A much higher prevalence varying between 28 and $45 \%$ was seen in large-scale studies from other parts of the world [16-18]. In our study, amongst patients hospitalised with COVID-19, we found a $7.2 \%$ prevalence of AKI. Between May and September 2020, our centre admitted COVID-19 patients with varying severity of illness. Our study population consisted of patients with mild, moderate and severe COVID-19. The lower percentage of AKI in our
Table 3 Factors associated with AKD at the time of discharge (univariable and multivariable regression analyses)

\begin{tabular}{lll}
\hline Clinical characteristic & OR (univariable) & OR (multivariable) \\
\hline Age in years & $1.04(1.01-1.07, p=0.013)$ & $1.02(0.99-1.07, p=0.215)$ \\
Hypertension & $3.59(1.58-8.70, p=0.003)$ & $2.87(1.04-8.52, p=0.047)$ \\
Heart disease & $4.86(1.88-13.76, p=0.002)$ & $5.87(1.66-23.54, p=0.008)$ \\
AKI at presentation & $0.37(0.14-0.92, p=0.036)$ & $0.25(0.07-0.80, p=0.023)$ \\
Severe albuminuria & $3.87(1.62-9.72, p=0.003)$ & $5.47(1.91-16.99, p=0.002)$ \\
\hline
\end{tabular}


study compared to recent studies from western literature could be attributable to this heterogeneity in patient population. Amongst other studies evaluating AKI prevalence in hospitalised patients with COVID-19 [16-18], 25.6-30\% of patients needed ICU care as compared to only $4.4 \%$ from our study. Our rate of AKI does corroborate with another recent study from India [8] which found an incidence of $7 \%$ in hospitalised patients with AKI, although percentage requiring ICU care was not specified in this study. The low overall severity of COVID in our patients could also explain the lower percentage of stage $3(13.7 \%)$ AKI in our study compared to previous studies which had between 31.1-66\% of stage 3 AKI patients [8, 16-18].

With regard to timing of AKI, we found that $72.6 \%$ of our patients had AKI at the time of admission. In a study by Hirsch et al., there was a higher probability of having AKI at time of admission or within $24 \mathrm{~h}$ of admission. They also found an increased probability of AKI diagnosis at the time of initiation of mechanical ventilation and hence proposed that ischaemic acute tubular injury may have been the aetiology of AKI in their patients. Indeed, acute tubular injury has been proposed as the most common cause of AKI in COVID-19 [2]. Although we did find a very high percentage of patients having AKI at admission, the aetiology of AKI in our patients could not be ascertained keeping in mind the retrospective and observational nature of our study.

Acute kidney injury has been seen to be associated with a higher mortality amongst patients of COVID-19 [17, 19]. Worse survival outcomes have been seen in patients with higher stages of AKI [17, 19]. In our study, amongst patients who developed AKI, 29.5\% required ICU care and $22.6 \%$ required mechanical ventilation. Mortality in patients who developed AKI was $22.1 \%$ overall and $74.5 \%$ in those who required ICU. We found that amongst patients who developed AKI, a higher age, stage $3 \mathrm{AKI}$ and need for mechanical ventilation was associated with mortality. A higher stage of AKI has been earlier seen to be associated with higher mortality in previous studies which describe an increasing risk for mortality with increasing stage of AKI $[18,20]$. The overall lower mortality rate in AKI in our patients compared to other studies $[16,18]$ which quote a mortality between 35 and $50 \%$ could again be due to lower percentage of patients requiring ICU care and more patients having a lower stage of AKI as compared to that in other studies. Mortality in patients requiring RRT (75\%) was similar to that found in other studies $[17,18]$.

Acute kidney injury if persistent may evolve into acute kidney disease and chronic kidney disease, the three entities now being considered as a continuum [20]. Recovery of renal function after AKI has often been neglected as an endpoint in studies [21] and various definitions have been proposed for recovery from AKI [22, 23]. Amongst patients not known to have prior kidney disease, we estimated the percentage who had recovery of acute kidney injury versus those who did not at the time of discharge. We considered recovery from AKI as a return to baseline expected serum creatinine at an eGFR $75 \mathrm{~mL} / \mathrm{min} / 1.73 \mathrm{~m}^{2}$. Those who did not recover kidney function completely were considered to have acute kidney disease (AKD). We found that 59.1\% patients had recovery of AKI leaving $40.9 \%$ of patients with acute kidney disease at the time of discharge. In a study by Chan et al., a similar percentage of patients (35\%) were seen to have AKD at discharge [17]. Risk factors for acute kidney disease at the time of discharge identified in our study included pre-existing heart disease and severe albuminuria during admission. The presence of acute kidney disease in a large percentage of discharged patients emphasises the need for post-COVID care clinics with close follow-up of such patients focussing not only on pulmonary but also kidney rehabilitation. It is to be noted that we did not have baseline pre-admission creatinine values for our patients, and hence, this could be an overestimation of the percentage having acute kidney disease at the time of discharge.

We also found that patients who had AKI at presentation to the hospital had a higher chance of recovery of renal function at the time of discharge than those who developed in-hospital AKI. This may be either due to a lead time effect leading to better renal function at time of discharge or maybe due to a more severe kidney injury in those with in-hospital AKI.

Our study has certain strengths. First, we had a large sample size of patients. Second, we had outcome data for $100 \%$ of the patients at the time of analysis. Limitations of our study include its observational and retrospective nature. Another limitation of our study is the lack of follow-up of renal function status post-discharge.

In conclusion, we found a low prevalence of AKI in COVID-19 in our study population. Risk factors associated with mortality in those with AKI included higher age, stage $3 \mathrm{AKI}$ and need for mechanical ventilation. Amongst survivors, a significant percentage had acute kidney disease at the time of discharge. This study emphasises the need for close follow-up of patients who develop AKI during hospitalisation with COVID-19.

\section{Declarations}

Conflict of interest The authors have declared that no conflict of interest exists.

Ethical approval All the procedures performed in studies involving human participants were in accordance with the ethical standards of 
the institutional ethical committee at which the studies were conducted (IEC Approval number CSP-MED/20/NOV/63/164) and with the 1964 Helsinki Declaration and its later amendments or comparable ethical standards.

Informed consent Not applicable, given the retrospective nature of study using electronic medical records.

\section{References}

1. AlSamman M, Caggiula A, Ganguli S, Misak M, Pourmand A. Non-respiratory presentations of COVID-19, a clinical review. Am J Emerg Med. 2020;38(11):2444-54. https://doi.org/10. 1016/j.ajem.2020.09.054 (Epub 2020 Sep 24. PMID: 33039218; PMCID: PMC7513760).

2. Ng JH, Bijol V, Sparks MA, Sise ME, Izzedine H, Jhaveri KD. Pathophysiology and pathology of acute kidney injury in patients with COVID-19. Adv Chronic Kidney Dis. 2020;27(5):365-76. https://doi.org/10.1053/j.ackd.2020.09.003 (Epub 2020 Oct 20. PMID: 33308501; PMCID: PMC7574722).

3. Silver SA, Beaubien-Souligny W, Shah PS, Harel S, Blum D, Kishibe T, Meraz-Munoz A, Wald R, Harel Z. The prevalence of acute kidney injury in patients hospitalized with COVID-19 infection: a systematic review and meta-analysis. Kidney Med. 2021;3(1):83-98.e1. https://doi.org/10.1016/j.xkme.2020.11.008 (Epub 2020 Dec 9. PMID: 33319190; PMCID: PMC7723763).

4. WHO COVID-19 Dashboard. Geneva: World Health Organization, 2020. Available online https://covid19.who.int/ (last cited: 15-06-2021).

5. Chopra S, Saha A, Kumar V, Thakur A, Pemde H, Kapoor D, Ray S, Das A, Pandit K, Gulati A, Sharma AG, Singh P, Sodani R. Acute Kidney Injury in Hospitalized Children with COVID19. J Trop Pediatr. 2021;67(2):fmab037. https://doi.org/10.1093/tropej/ fmab037 (PMID: 34080011).

6. Aggarwal A, Shrivastava A, Kumar A, Ali A. Clinical and epidemiological features of SARS-CoV-2 patients in SARI ward of a tertiary care centre in New Delhi. J Assoc Physicians India. 2020;68(7):19-26 (PMID: 32602676).

7. Sundaram S, Soni M, Annigeri R. Urine abnormalities predict acute kidney injury in COVID-19 patients: An analysis of 110 cases in Chennai. South India Diabetes Metab Syndr. 2021;15(1):187-91. https://doi.org/10.1016/j.dsx.2020.12.021 (Epub 2020 Dec 19. PMID: 33383438; PMCID: PMC7832278).

8. Sampathkumar, Hanumaiah H, Rajiv A, Shakthi Kumar, Sampathkumar D, Senthilkumar, Kumar H, Karthikeyan Incidence, risk factors and outcome of COVID-19 associated AKI — a study from South India. J Assoc Physicians India. 2021;69:28-31.

9. Kidney Disease. Improving Global Outcomes (KDIGO) Acute Kidney Injury Work Group. KDIGO clinical practice guideline for acute kidney injury. Kidney Int Suppl. 2012;2012(2):1-36.

10. Indian Council of Medical Research. Clinical management protocol: COVID-19 [Table 1, p. 4, 5]. Available online: https://www. mohfw.gov.in/pdf/ClinicalManagementProtocolforCOVID19.pdf (2021)

11. Guan WJ, Ni ZY, Hu Y, Liang WH, Ou CQ, He JX, Liu L, Shan H, Lei CL, Hui DSC, Du B, Li LJ, Zeng G, Yuen KY, Chen RC, Tang CL, Wang T, Chen PY, Xiang J, Li SY, Wang JL, Liang ZJ, Peng YX, Wei L, Liu Y, Hu YH, Peng P, Wang JM, Liu JY, Chen Z, Li G, Zheng ZJ, Qiu SQ, Luo J, Ye CJ, Zhu SY, Zhong NS, China Medical Treatment Expert Group for Covid-19. Clinical characteristics of coronavirus disease 2019 in China. N Engl J Med. 2020;382(18):1708-20. https://doi.org/10.1056/NEJMo a2002032 (Epub 2020 Feb 28. PMID: 32109013; PMCID: PMC7092819).

12. Huang C, Wang Y, Li X, Ren L, Zhao J, Hu Y, Zhang L, Fan G, Xu J, Gu X, Cheng Z, Yu T, Xia J, Wei Y, Wu W, Xie X, Yin W, Li H, Liu M, Xiao Y, Gao H, Guo L, Xie J, Wang G, Jiang R, Gao Z, Jin Q, Wang J, Cao B. Clinical features of patients infected with 2019 novel coronavirus in Wuhan. China Lancet. 2020;395(10223):497-506. https://doi.org/10.1016/S01406736(20)30183-5 (Epub 2020 Jan 24. Erratum in: Lancet. 2020 Jan 30; PMID: 31986264; PMCID: PMC7159299).

13. Cai Q, Huang D, Ou P, Yu H, Zhu Z, Xia Z, Su Y, Ma Z, Zhang Y, Li Z, He Q, Liu L, Fu Y, Chen J. COVID-19 in a designated infectious diseases hospital outside Hubei Province, China. Allergy. 2020;75(7):1742-52. https://doi.org/10.1111/all.14309 (Epub 2020 Apr 17 PMID: 32239761).

14. Liu J, Zhang L, Chen Y, Wu Z, Dong X, Teboul JL, Zhang S, Ye X, Liu Y, Wang T, Du H, Li W, Chen D. Association of sex with clinical outcomes in COVID-19 patients: a retrospective analysis of 1190 cases. Respir Med. 2020;173:106159. https://doi. org/10.1016/j.rmed.2020.106159 (Epub 2020 Sep 28. PMID: 33010731; PMCID: PMC7521447).

15. Shi S, Qin M, Shen B, Cai Y, Liu T, Yang F, Gong W, Liu X, Liang J, Zhao Q, Huang H, Yang B, Huang C. Association of cardiac injury with mortality in hospitalized patients with COVID-19 in Wuhan, China. JAMA Cardiol. 2020;5(7):80210. https://doi.org/10.1001/jamacardio.2020.0950 (PMID: 32211816; PMCID: PMC7097841).

16. Hirsch JS, Ng JH, Ross DW, Sharma P, Shah HH, Barnett RL, Hazzan AD, Fishbane S, Jhaveri KD, Northwell COVID19 Research Consortium; Northwell Nephrology COVID-19 Research Consortium. Acute kidney injury in patients hospitalized with COVID-19. Kidney Int. 2020;98(1):209-18. https://doi.org/10.1016/j.kint.2020.05.006 (Epub 2020 May 16. PMID: 32416116; PMCID: PMC7229463).

17. Chan L, Chaudhary K, Saha A, Chauhan K, Vaid A, Zhao S, Paranjpe I, Somani S, Richter F, Miotto R, Lala A, Kia A, Timsina P, Li L, Freeman R, Chen R, Narula J, Just AC, Horowitz C, Fayad Z, Cordon-Cardo C, Schadt E, Levin MA, Reich DL, Fuster V, Murphy B, He JC, Charney AW, Böttinger EP, Glicksberg BS, Coca SG, Nadkarni GN. Mount Sinai COVID Informatics Center (MSCIC) AKI in hospitalized patients with COVID19. J Am Soc Nephrol. 2021;32(1):151-60. https://doi.org/10. 1681/ASN.2020050615 (Epub 2020 Sep 3. PMID: 32883700; PMCID: PMC7894657).

18. Mohamed MMB, Lukitsch I, Torres-Ortiz AE, Walker JB, Varghese V, Hernandez-Arroyo CF, Alqudsi M, LeDoux JR, Velez JCQ. Acute kidney injury associated with coronavirus disease 2019 in Urban New Orleans. Kidney 360. 2020;1(7):614-22.

19. Ng JH, Hirsch JS, Hazzan A, Wanchoo R, Shah HH, Malieckal DA, Ross DW, Sharma P, Sakhiya V, Fishbane S, Jhaveri KD, Northwell Nephrology COVID-19 Research Consortium. Outcomes among patients hospitalized with COVID-19 and acute kidney injury. Am J Kidney Dis. 2021;77(2):204-2151. https://doi.org/10.1053/j.ajkd.2020.09.002 (Epub 2020 Sep 19. PMID: 32961245; PMCID: PMC7833189).

20. Chawla LS, Bellomo R, Bihorac A, Goldstein SL, Siew ED, Bagshaw SM, Bittleman D, Cruz D, Endre Z, Fitzgerald RL, Forni L, Kane-Gill SL, Hoste E, Koyner J, Liu KD, Macedo E, Mehta R, Murray P, Nadim M, Ostermann M, Palevsky PM, Pannu N, Rosner M, Wald R, Zarbock A, Ronco C, Kellum JA, Acute Disease Quality Initiative Workgroup 16. Acute kidney disease and renal recovery: consensus report of the Acute Disease Quality Initiative (ADQI) 16 Workgroup. Nat Rev Nephrol. 2017;13(4):241-57. https://doi.org/10.1038/nrneph.2017.2 (Epub 2017 Feb 27. PMID: 28239173). 
21. Ronco C, Ferrari F, Ricci Z. Recovery after acute kidney injury: a new prognostic dimension of the syndrome. Am J Respir Crit Care Med. 2017;195(6):711-4. https://doi.org/10.1164/rccm. 201610-1971ED (PMID: 28294655).

22. Kellum JA, Sileanu FE, Bihorac A, Hoste EA, Chawla LS. Recovery after acute kidney injury. Am J Respir Crit Care Med. 2017;195(6):784-91. https://doi.org/10.1164/rccm.2016040799OC (PMID: 27635668; PMCID: PMC5363967).

23. Duff S, Murray PT. Defining early recovery of acute kidney injury. Clin J Am Soc Nephrol. 2020;15(9):1358-60. https://doi.org/10.
2215/CJN.13381019 (Epub 2020 Apr 1. PMID: 32238366; PMCID: PMC7480548).

Publisher's Note Springer Nature remains neutral with regard to jurisdictional claims in published maps and institutional affiliations. 